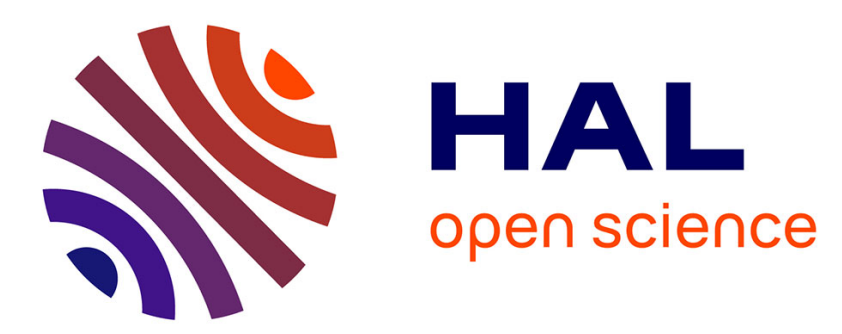

\title{
An application of a centralized model predictive control on microgrids
}

Khaled Hajar, Ahmad Hably, Seddik Bacha, Ahmad Elrafhi, Ziad Obeid

\section{To cite this version:}

Khaled Hajar, Ahmad Hably, Seddik Bacha, Ahmad Elrafhi, Ziad Obeid. An application of a centralized model predictive control on microgrids. EPEC 2016 - IEEE Electrical Power and Energy Conference, Oct 2016, Ottawa, Canada. hal-01385578

\section{HAL Id: hal-01385578 https://hal.science/hal-01385578}

Submitted on 21 Oct 2016

HAL is a multi-disciplinary open access archive for the deposit and dissemination of scientific research documents, whether they are published or not. The documents may come from teaching and research institutions in France or abroad, or from public or private research centers.
L'archive ouverte pluridisciplinaire HAL, est destinée au dépôt et à la diffusion de documents scientifiques de niveau recherche, publiés ou non, émanant des établissements d'enseignement et de recherche français ou étrangers, des laboratoires publics ou privés. 


\title{
An application of a centralized model predictive control on microgrids
}

\author{
Khaled Hajar ${ }^{*+}$, Ahmad Hably ${ }^{*}$, Seddik Bacha *, Ahmad Elrafhi ${ }^{\diamond}$, Ziad Obeid ${ }^{\diamond}$ \\ *Univ. Grenoble Alpes, GIPSA-Lab \\ F-38000 Grenoble, France. \\ khaled.hajar@gipsa-lab.grenoble-inp.fr \\ $\diamond$ Universite de Technologie et de Sciences Appliquees Libano-Francaise - Lebanon.
}

\begin{abstract}
In this paper, a centralized model predictive control (MPC) is applied on a group of interconnected microgrids (MGs) with the main grid. The objective is to maximize the benefits for all the elements constituting the MGs in addition to the benefits of the main grid. The application of MPC in our study needs a forecasting information about energy prices, production power, and loads. The algorithm is tested on five interconnected MGs connected to the main grid. Results have shown the performance of the proposed algorithm, especially for the benefits of MG owners, the coordination between MGs while respecting of the constraints related to each one of them.
\end{abstract}

\section{INTRODUCTION}

A small-scale power supply network where small communities are provided by their own power is named microgrid (MG). A MG contains loads, distributed generation (DG), renewable energy sources (RES) and energy storage systems (ESS) like electrical vehicles, hydraulic storage, batteries, etc. Microgrid applications have different objectives and characteristics but they all share some common technical problems due to the use of RES. These RES have an intermittent, random, non programmable nature, which makes them difficult to provide a continuous power supply to isolated loads and to assure energy dispatch of RES in distribution grids [1].

MGs can be considered as intelligent distribution systems with two different modes of operation: the isolated mode and the grid-connected mode [2]. However, it is also expected to provide sufficient generation capacity, controls and operational strategies to supply at least a portion of the load, after being disconnected from the distribution system and remains operational as an autonomous (isolated) entity [3].

The general objective of energy management of a microgrid is to minimize operating costs such as fuel, maintenance, and the purchased cost of exchange power from the main grid [4]. As for the distribution system operators (DSO), the presence of MGs provides many advantages. The DSO and MGs owners can benefit from the lower operation costs. The customers can benefit from a more reliable and economical power supply. Therefore, it is necessary to consider the DSO and networked MGs altogether [5].

There are several works that address MPC and optimization of a network of MGs. In [6], an MPC has been proposed where controllers are supposed to operate separately but their design is based on a global model of the overall system.
In [7], the authors have proposed an MPC for the optimal power exchanges in a smart network of MGs. Falahi et al. [8] proposed an MPC based energy management system to regulate the active and reactive power in a microgrid. An investigation on decentralized linear quadratic Gaussian control (LQG) approach has been made in [9].

In this present paper, we apply a centralized MPC of the power flow among a network of MGs and with DSO. This study is based on the economic profit of all the actors of the Grid (DSO and all the MGs) while minimizing the exchange between MGs and DSO from one side, and maximizing the use of renewable energy in each $\mathrm{MG}$ and the exchange of power between neighboring MGs from the other side. The paper is organized as follows. In Section II, MG units are presented. MG modeling as well as MPC problem are developed in Section III. The results of the application of the methodology are presented and commented in Section IV. Section V provides some conclusions and perspectives.

\section{MICROGRID UNITS}

Several models for MG have been proposed in previous studies. We have used the modeling procedure proposed by [10] to create our model of MG. Energy storage systems (ESS), photovoltaic (PV), wind power, local loads and distributed generation are integrated in each MG. The variation of wind speed and solar irradiance affect the wind power and PV efficiency respectively. Depending on the loads and

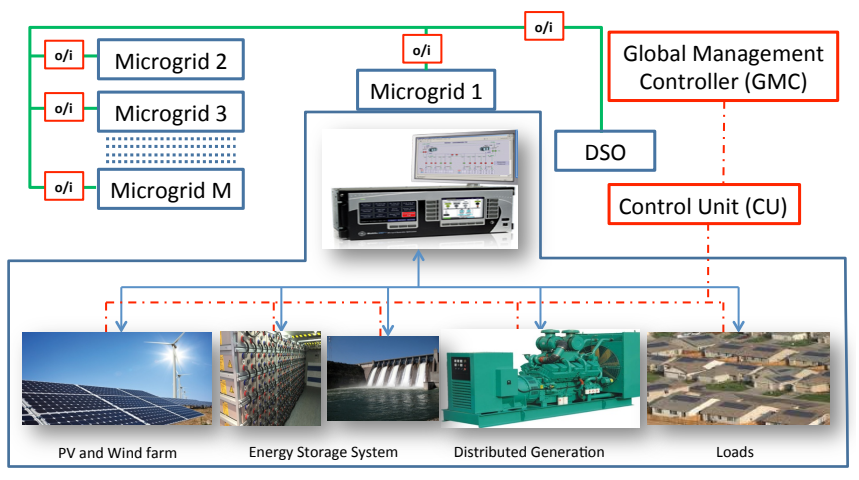

Fig. 1: Microgird elements. 
the production ESS has two status: charging and discharging. In our previous work [11], a control unit (CU) is used in order to maximize the power stored in ESS to assure the local consumption. Global Management Controller (GMC) is notified of the state of $\mathrm{CU}$ which optimize the control of each MG. It verifies if the MG has excess of power or viseversa. For each MG the goal can be achieved by controlling the charge/discharge of ESS, starting or stopping DG, and receiving/sending power from/to neighboring MGs. The GMC is dedicated to manage the power in the grid, the relation between MGs as well as with the DSO with a predicted control. It takes also the decision wherever the excess power is to be sent to other MGs or to DSO. The different elements of MG are presented in Fig.1 from our previous work [1]. This figure also shows the units of producing or consuming energy. A microgrid can also be connected or disconnected from DSO or/and can be connected to other MGs.

To summarize, an MG integrates:

- DSO providing/purchasing power for/from the MGs.

- Loads representing consumers demand.

- RES providing renewable energy.

- ESS improving the quality, and reliability of supply.

- DG improving the reliability of supply.

- Control Unit (CU) transferring the data to GMC.

\section{MiCROGRID MODELING AND OPTIMIZATION}

\section{A. MPC algorithm steps}

The MPC is a control strategy that is suitable for optimizing the performance of constrained systems. Constraints are present in all control systems. Through handling of constraints, MPC can improve the performance of a system by allowing it to safely operate near constraint boundaries. To apply MPC, some steps must be followed. At the first step of time $t$, the system actual state is taken as the initial point of the problem as the RES, ESS, Loads, power generation. Then, for the control horizon $N_{c}$ we compute an optimal control sequence for the next prediction period $N_{p}$ based on RES, ESS, Loads, power generation in addition to the prediction of energy price. After that the first control step of all MGs will be applied. Finally, an update is made for all the information for next time step while moving to the next sampling time to re-apply the same optimization.

\section{B. Modeling}

Figure 2 shows the interaction among MGs on one hand and between DSO and MGs on the other hand. The power flow is as the following:

- $P_{S, D}$ : Predicted power sold by the DSO (kW).

- $P_{S, M}$ : Predicted power sold by the MG $(\mathrm{kW})$.

- $P_{B, D}$ : Predicted power bought by the DSO $(\mathrm{kW})$.

- $P_{B, M}$ : Predicted power bought by the MG $(\mathrm{kW})$.

- $P_{e q}$ : Power equilibrium.

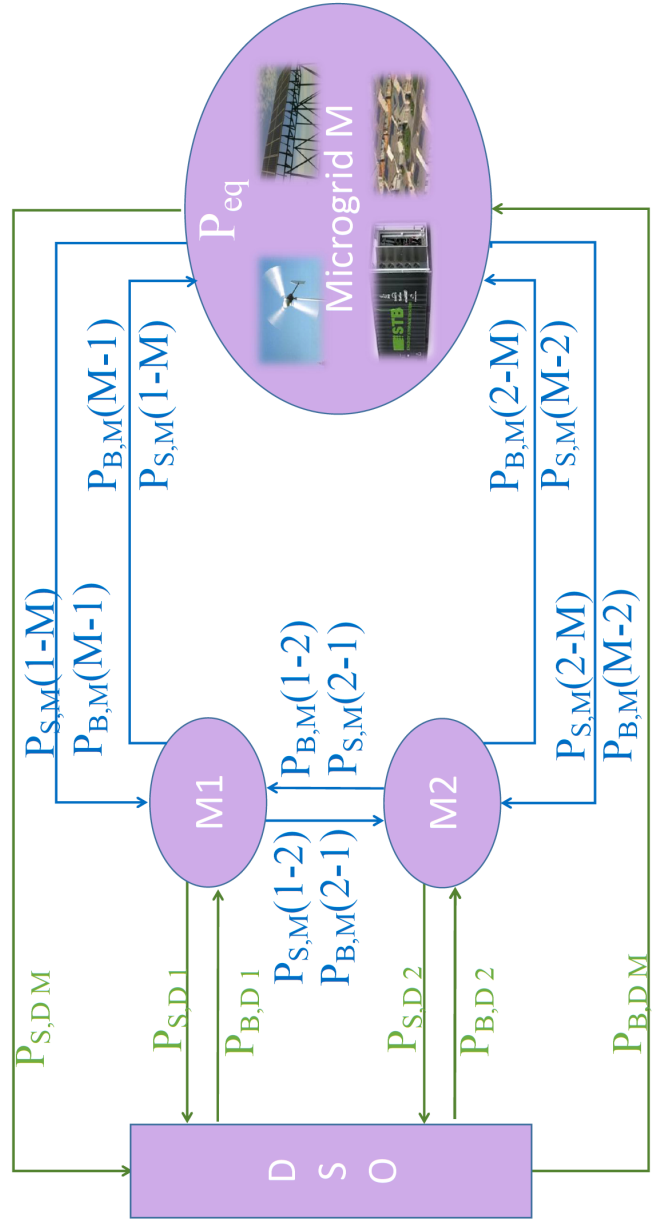

Fig. 2: Power flow in the grid (MG+DSO).

The stored energy equation in each MG:

$$
\begin{aligned}
x(m, t+k)= & x(m, t+k-1)- \\
& \delta_{\text {dis }, m} E_{\text {dis }}(m, t+k)+ \\
& \delta_{\text {char }, m} E_{\text {char }}(m, t+k)
\end{aligned}
$$

where

- $x$ : Stored energy $(\mathrm{kWh})$.

- $\delta_{d i s, m}$ : Discharging efficiency of the ESS in the m-th MG.

- $\delta_{\text {char }, m}$ : Charging efficiency of the ESS in the m-th MG.

- $E_{\text {dis }}$ : Discharged energy $(\mathrm{kWh})$.

- $E_{\text {cha }}$ : Charged energy $(\mathrm{kWh})$.

\section{Optimization Formulation}

A nonlinear centralized optimization is used to formulate the energy management in MG. Our objective is to optimize the grid in a predictive way that the power generation, power balance, ESS, energy exchange between MGs are satisfied under certain constraints that will be presented later. The cost 
function $F$ to be minimized is given by the following equation:

$$
\begin{array}{r}
F=\sum_{k=1}^{N_{c}} \sum_{m=1}^{M} \sum_{n, n \neq m}^{M}\left[\psi_{M}(k) P_{S, M}(m, n, t+k) T_{S, M}(n, t+k)\right. \\
\left.-\hat{\psi}_{M}(k) P_{B, M}(m, n, t+k) T_{B, M}(n, t+k)\right] \\
+\sum_{k=1}^{N_{c}} \sum_{m=1}^{M}\left[\psi_{D}(k) P_{S, D}(m, t+k) T_{S, D}(m, t+k)\right. \\
\left.-\hat{\psi}_{D}(k) P_{B, D}(m, t+k) T_{B, D}(m, t+k)\right]
\end{array}
$$

with

- $m, n$ : MG index.

- $M:$ MGs number.

- $t$ : Control step.

- $N_{c}$ : Control horizon.

- $k$ : Prediction step.

- $\hat{\psi}_{M}(k)$ : Scale factor of buying power from the MGs.

- $\psi_{M}(k)$ : Scale factor of selling power to the MGs.

- $\hat{\psi}_{D}(k)$ : Scale factor of buying power from DSO.

- $\psi_{D}(k)$ : Scale factor of selling power to DSO.

- $T_{S, D}$ : Expected tariff value of selling energy by the DSO $(€ / \mathrm{kWh})$.

- $T_{S, M}$ : Expected tariff value of selling energy by the MG $(€ / \mathrm{kWh})$.

- $T_{B, D}$ : Expected tariff value of buying energy by the DSO $(€ / \mathrm{kWh})$.

- $T_{B, M}$ : Expected tariff value of buying energy by the $\mathrm{MG}$ $(€ / \mathrm{kWh})$.

As described in Fig. 2, both terms in the objective function are related to energy sold or bought. The first term concern neighboring MGs and the second one concerns the DSO. In the following section we introduce the constraints for this optimization problem.

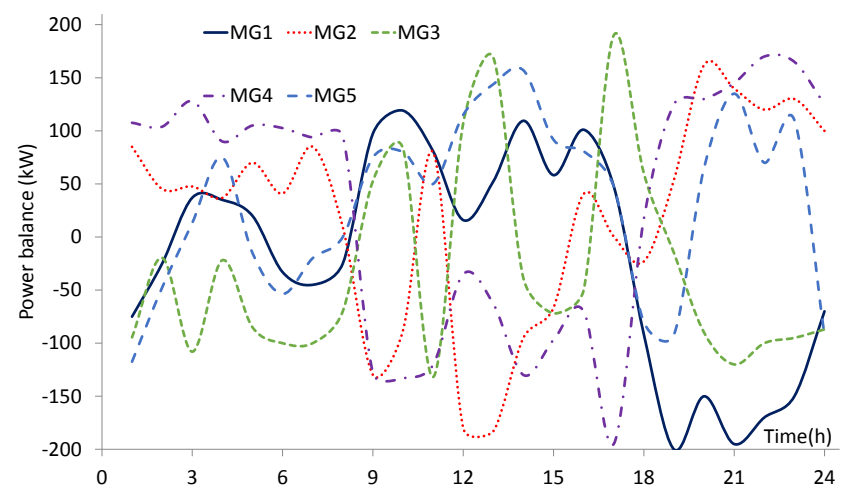

Fig. 3: MGs power equilibrium.

\section{Constraints}

First, we must consider that the power sold by the m-th MG is equal the power bought by the $\mathrm{n}$-th $\mathrm{MG}$ :

$$
P_{B, M}(m, n, t+k)=P_{S, M}(n, m, t+k)
$$

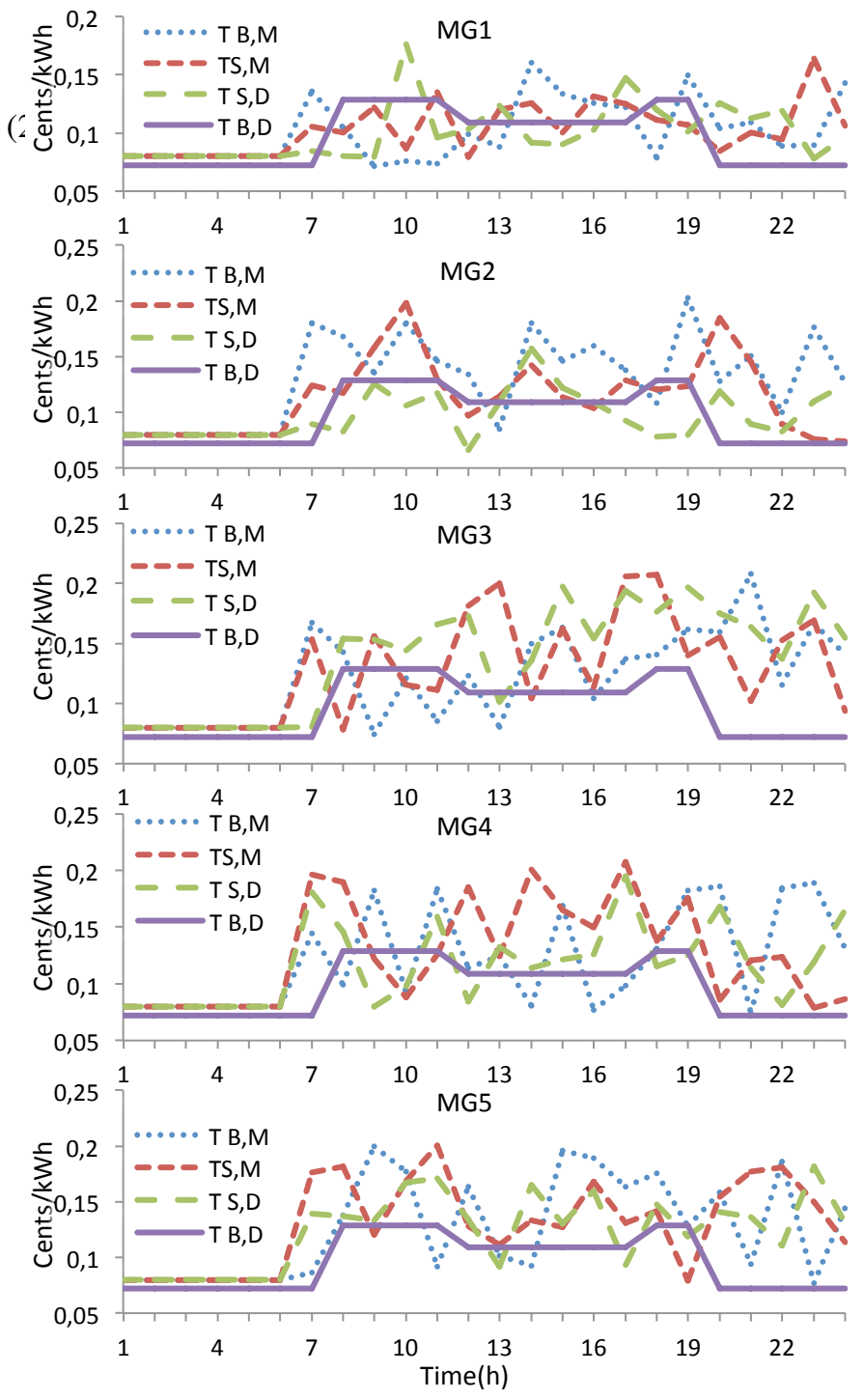

Fig. 4: The tariff vector.

An upper and a lower bound $\left(P_{S, D, \min }, P_{S, D, \max }\right)$ constrained the predicted power sold to the DSO in each MG:

$$
P_{S, D, \min } \leq P_{S, D}(m, t+k) \leq P_{S, D, \max }
$$

Also the predicted power bought from the DSO is also constrained by an upper and lower bound $\left(P_{B, D, \min }, P_{B, D, \max }\right)$

$$
P_{B, D, \min } \leq P_{B, D}(m, t+k) \leq P_{B, D, \max }
$$

An upper and a lower bound $\left(x_{m, \min }, x_{m, \max }\right)$ constrained the stored energy in each ESS. In the m-th MG:

$$
x_{m, \min } \leq x(m, t+k) \leq x_{m, \max }
$$

The charging power must be lower than certain limited power value $P_{\text {charmax } m}$ :

$$
0 \leq P_{\text {char }}(m, t+k) \leq P_{\text {charmax }, m}
$$




\begin{tabular}{|c|c|c|c|c|c|}
\hline & MG1 & MG2 & MG3 & MG4 & MG5 \\
\hline$P_{S, D, \min }(\mathrm{kW})$ & 450 & 550 & 600 & 350 & 450 \\
$P_{B, D, \min }(\mathrm{kW})$ & 400 & 400 & 450 & 500 & 450 \\
ESS initial(kW) & 80 & 70 & 40 & 30 & 20 \\
$x_{m, \max }(\mathrm{kW})$ & 100 & 90 & 100 & 95 & 90 \\
$\delta_{\text {dis, }}$ & 0.7 & 0.7 & 0.8 & 0.8 & 0.5 \\
$\delta_{\text {cha,m }}$ & 0.7 & 0.5 & 0.6 & 0.5 & 0.3 \\
\hline
\end{tabular}

TABLE I: Numerical value used for simulation

Also the discharging power must be lower than certain limited power value $P_{\text {dismax }, m}$ :

$$
0 \leq P_{\text {dis }}(m, t+k) \leq P_{\text {dismax }, m}
$$

At last an MG cannot buy and sell energy at the same time. buying can be done when the MG is in need of power otherwise MG can sell power when its production is higher than its consumption:

- If $\Delta P_{M G, n}(t+k)>0$ then $P_{B, D}(m, t+k)=0$ and $P_{B, M}(n, m, t+k)=0$

- If $\Delta P_{M G, n}(t+k)<0$ then $P_{S, D}(m, t+k)=0$ and $P_{S, M}(n, m, t+k)=0$

with $\Delta P_{M G, n}(t+k)=\sum\left(P_{E P, n}(t+k)-P_{E L, n}(t+k)\right)$, Where

- $\Delta P_{M G, n}$ : Power equilibrium of $\mathrm{n}$-th $\mathrm{MG}$ at $(t+k)$ instant.

- $P_{E P, n}$ : Power of the expected production of $\mathrm{n}$-th $\mathrm{MG}$ at $(t+k)$ instant.

- $P_{E L, n}$ : Power of the expected load of $\mathrm{n}$-th MG at $(t+k)$ instant.

\section{E. Numerical values}

The values used in simulation are given in Table I. They give global values for some power constraints and some characteristics of ESS. The maximal capacity of the ESS available in each MG is comprised between 20 and $100 \mathrm{kWh}$. For each MG, the maximal charge and discharge powers are limited. As example, MG5 can discharge in 2 hours $\left(\delta_{d i s, m}=0.5\right)$ and need more than 3 hours to be full charged $\left(\delta_{c h a, m}=0.3\right)$.

\section{Simulation Results}

The above described optimization problem has been implemented in Matlab. We have used a modified version of the study case presented in [12]. The simulation will take in consideration five interconnected MGs with $N_{c}=3$ and $N_{p}=24$. When the supply in a MG is less the demand, the solution is to discharge the ESS or purchase power from DSO or many neighbors MG. Each MG generates power and feeds a group of consumer in an interval time $(t, t+1)$. Also, it is connected to all neighboring MGs.

As for the tariff vector of selling and buying energy, $\left(T_{B, M}\right.$, $\left.T_{S, M}, T_{S, D}, T_{B, D}\right)$ are represented for each $\mathrm{MG}$ in a random value between $0.07 € / \mathrm{kWh}$ and $0.2 € / \mathrm{kWh}$ at day time, and $0.075 € / \mathrm{kW}$ from midnight to 6am (Fig. 4).

In Fig. 3, we show the predicted value of $P_{e q}$ for each MG. The value is calculated based on the load and production curves of [12] where we made some random calculation to

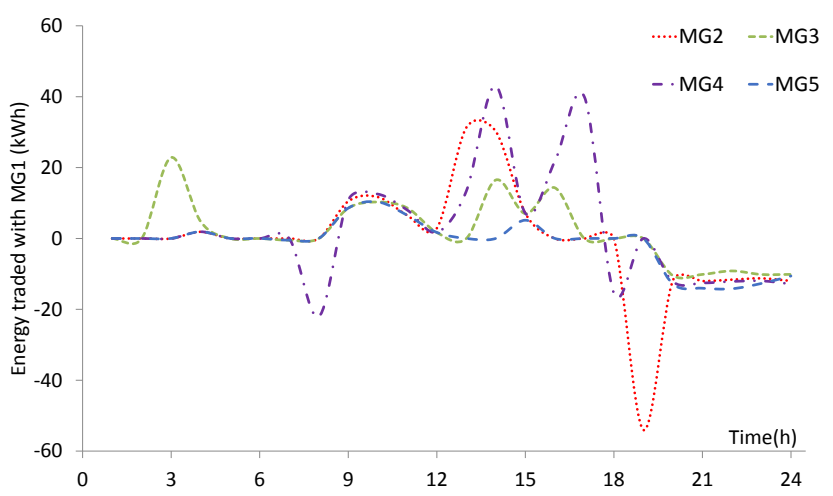

Fig. 5: Predictive control results for MG1.

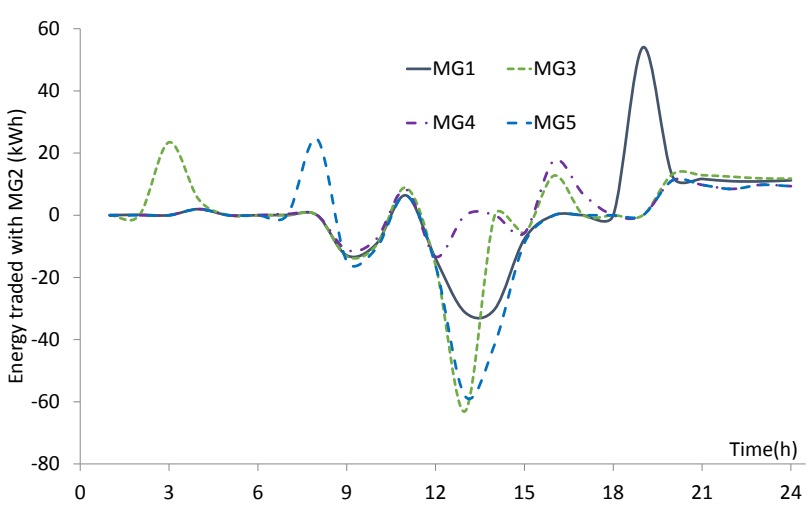

Fig. 6: Predictive control results for MG2.

create more MGs. The ESS can go from $25 \%$ to $90 \%$ of power storage. The power of ESS in each MG is different than the other. The sold and bought power from/to DSO is limited to $200 \mathrm{kWh}$ for each MG. The optimization algorithm searches to use the surplus power available in each MG, under constraints, and to be exchanged. If the constraints are not satisfied, the DSO interferes while respecting its constraints.

The optimal results shown in Fig.5 gives us an overview about the interaction of MG1 with the other MGs. As result of selling and buying, MG1 sells $396 \mathrm{kWh}$ in total especially $102 \mathrm{kWh}$ to MG2 and $94 \mathrm{kWh}$ to MG3, 35kWh for MG5 and finaly to MG4 $160 \mathrm{kWh}$. In addition, MG1 buys $112 \mathrm{kWh}$ from MG2, 99kWh from MG4,50kWh from MG3 and 64kWh MG5. So in total, MG1 buys 391kWh.

Fig.6 shows us the optimal energy exchanges of MG2. The total energy bought is $405 \mathrm{kWh}$, the main bought energy is from MG5 with $150 \mathrm{kWh}$, the rest of bought energy comes from MG1 and MG3 with $105 \mathrm{kWh}$ and $107 \mathrm{kWh}$ respectively.

Optimal energy strategy for MG3 is shown Fig.7. It is obvious that MG3 buys energy more than selling. In total, it buys $563 \mathrm{Kwh}$ from other MGs where the big amount comes from MG4 with $190 \mathrm{kWh}$, from MG5 $141 \mathrm{KWh}, 109 \mathrm{KWh}$ from MG2, and $114 \mathrm{kWh}$ from MG1. It sells an amount of $250 \mathrm{KWh}$ in total, distributed between MG2 and MG4 with $90 \mathrm{kWh}$ and $119 \mathrm{kWh}$ respectively. 


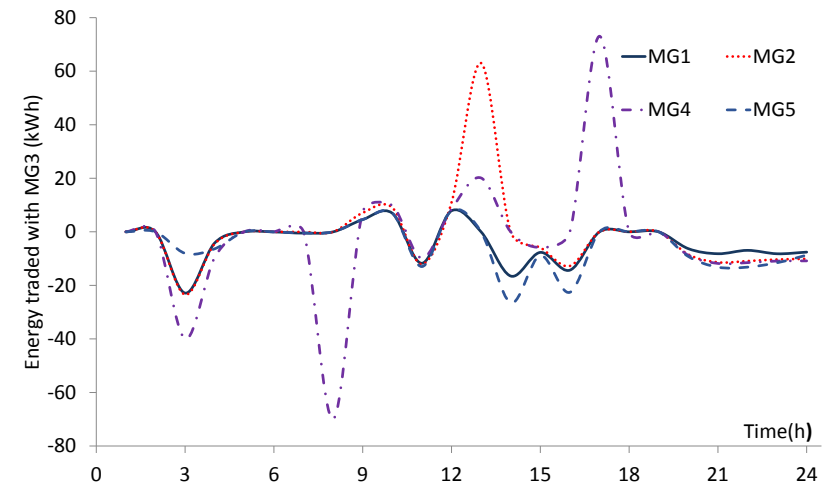

Fig. 7: Predictive control results for MG3.

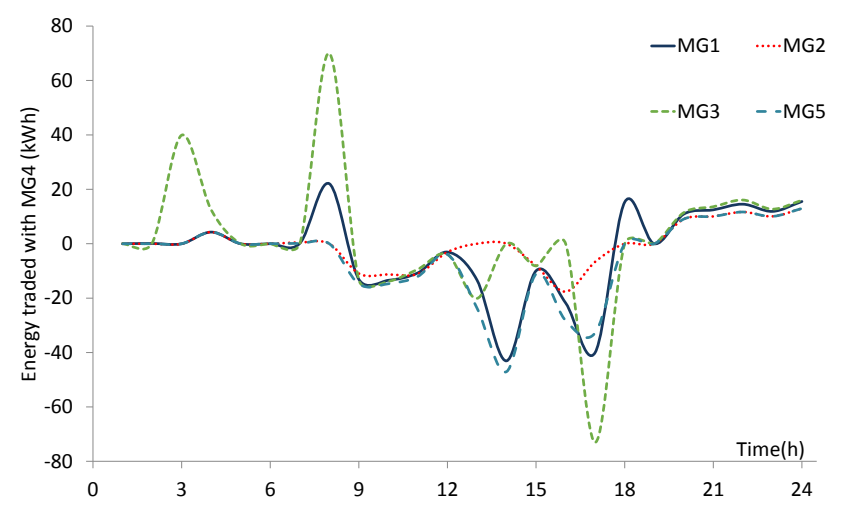

Fig. 8: Predictive control results for MG4.

For MG4 (Fig.8), the sold energy represents 422Kwh where MG3 buys $192 \mathrm{Kwh}$, MG1 buys $107 \mathrm{kWh}$ and finally MG5 and MG2 buy $58 \mathrm{kWh}$ for each one. Total bought energy is purchased from MG1 with $168 \mathrm{kWh}, \mathrm{MG} 268 \mathrm{kWh}, \mathrm{MG} 3$ $141 \mathrm{kWh}$ and MG5 188kWh.

MG5 represents the maximum benefit of sold/bought energy to other MGs with a total 668/57kWh (Fig.9).

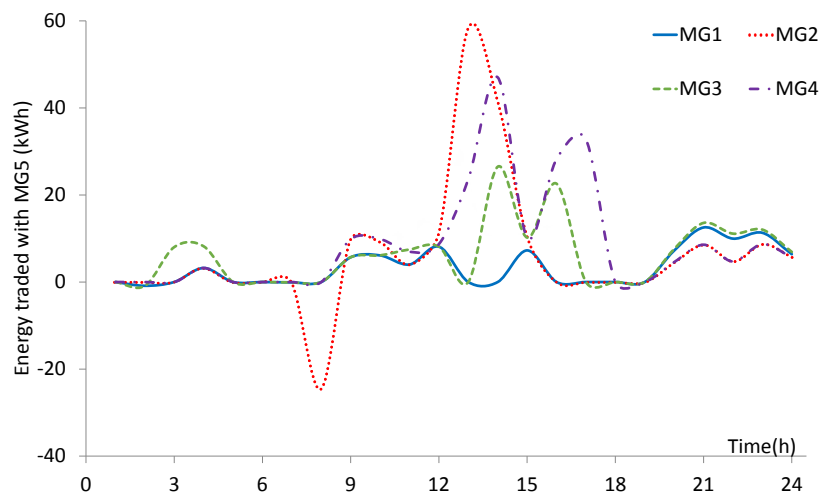

Fig. 9: Predictive control results for MG5.

Fig.10 gives us the interaction between MGs and DSO in terms of power exchange. Fig.11 reveals the total trade power in 24 hours between MGs in one hand and between MGs and
DSO in other hand. Finally, Fig.12 reveals the charge and

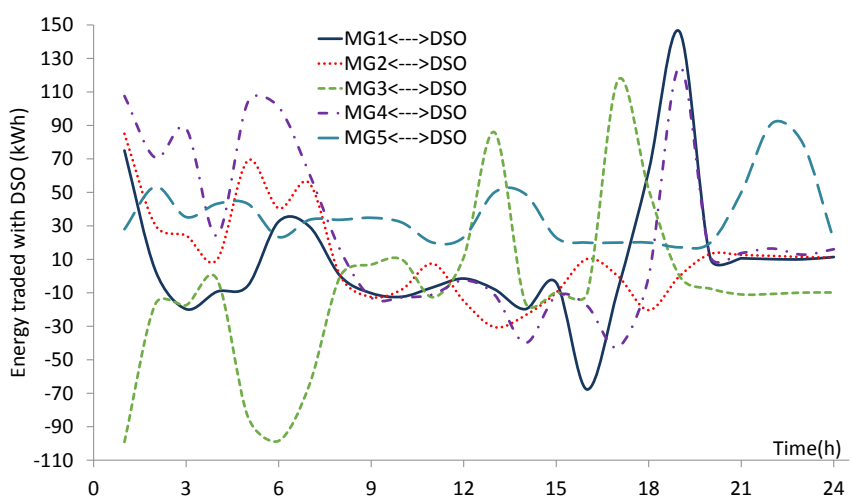

Fig. 10: Predictive power trade with DSO.

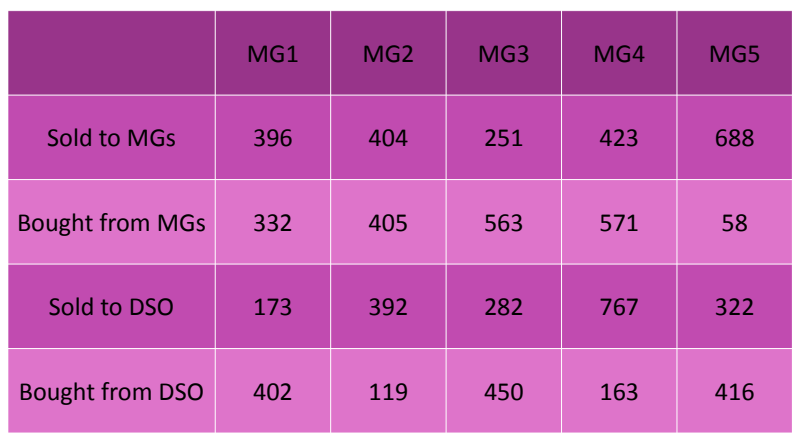

Fig. 11: Total predicted power exchange between MGs and DSO.

discharge of ESS in each MG

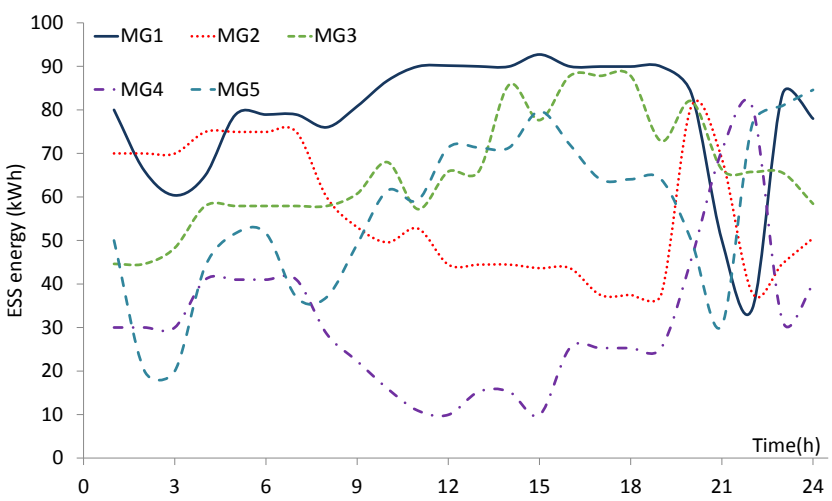

Fig. 12: Charge and discharge of ESS.

\section{A. Discussion on the results}

ESS charge and discharge of MG1 on Fig.12 shows between the hour 20 and 23 a brutal discharge and charge respectively. The discharge is due to the need of power at this time in MG1 and when the demand is covered by MG1 production unit or by purchasing power from neighboring MGs, the $\mathrm{CU}$ gives a command to charge the ESS of MG1. The time of charge and 
discharge is the same as $\delta_{d i s, 1}=\delta_{c h a, 1}$ (see Table I). On the same graph, it i s clear that the ESS value couldn't exceed the $90 \%$ of its total value, nor going beyond $25 \%$. A similar analysis can be done for other microgrids.

\section{CONCLUSiON}

The paper presents a model predictive control in a centralized manner to optimize the interaction between a network of MGs and DSO. Results have shown that the control performance of a network of MGs is achieved by maximizing the benefits of all the constituted elements of network. It is also shown the control of the ESS discharging/charging, and the predicted interaction of power exchange between MGs. The cooperation between MGs demonstrates its importance due to its benefit according the selling of the excess of power produced or its operation in standalone mode. A decentralized MPC version of this algorithm is under study. This control strategy can be used in case of failure of communication between microgrids.

\section{ACKNOWLEDGEMENT}

This work has been a joint collaboration by the project PARADISE which is sponsored by the National Research Agency (ANR).

\section{REFERENCES}

[1] K. Hajar, A. Hably, S. Bacha, A. Elrafhi, and Z. Obeid, "Optimal centralized control application on microgrids," in International Conference on Renewable Energies for Developing countries. IEEE.

[2] H. Al-Nasseri, M. Redfern, and R. O'Gorman, "Protecting micro-grid systems containing solid-state converter generation," in Future Power Systems, 2005 International Conference on. IEEE, 2005, pp. 5-pp.

[3] J. Shah, B. F. Wollenberg, and N. Mohan, "Decentralized power flow control for a smart micro-grid," in Power and Energy Society General Meeting, 2011 IEEE. IEEE, 2011, pp. 1-6.

[4] J. L. Yue Xiang and Y. Liu, "Robust energy management of microgrid with uncertain renewable generation and load," in IEEE TRANSACTIONS ON SMART GRID. IEEE, 2015, pp. 1-10.

[5] L. D. Ahmed Ouammi, Hanane Dagdougui and R. Sacile, "Coordinated model predictive-based power flows control in a cooperative network of smart microgrids," in IEEE TRANSACTIONS ON SMART GRID. IEEE, 2014, pp. 1-12.

[6] A. N. Venkat, I. A. Hiskens, J. B. Rawlings, and S. J. Wright, "Distributed mpc strategies with application to power system automatic generation control," Control Systems Technology, IEEE Transactions on, vol. 16, no. 6, pp. 1192-1206, 2008.

[7] M. E. M. Falahi, S. Lotfifard and K. Butler-Purry, "Decentralized energy management system for networked microgrids in grid-connected and islanded modes," in IEEE TRANSACTIONS ON POWER. IEEE, 2013, pp. 2217-2227.

[8] J. W. Zhaoyu Wang, Bokan Chen and J. Kim, "Dynamic model predictive-based energy management of dg integrated distribution systems," in IEEE TRANSACTIONS ON SMART GRID. IEEE, 2015, pp. $1-10$.

[9] K. De Brabandere, B. Bolsens, J. Van den Keybus, A. Woyte, J. Driesen, and R. Belmans, "A voltage and frequency droop control method for parallel inverters," Power Electronics, IEEE Transactions on, vol. 22, no. 4, pp. 1107-1115, 2007.

[10] A. J. del Real, A. Arce, and C. Bordons, "An integrated framework for distributed model predictive control of large-scale power networks," Industrial Informatics, IEEE Transactions on, vol. 10, no. 1, pp. 197209, 2014.

[11] K. Hajar, A. Hably, A. Elrafhi, Z. Obeid, and S. Bacha, "Optimization of a microgrid with renewable energy and distributed generation: A case study," in System Theory, Control and Computing (ICSTCC), 2015 19th International Conference on. IEEE, 2015, pp. 662-665.
[12] A. G. Tsikalakis and N. D. Hatziargyriou, "Centralized control for optimizing microgrids operation," in Power and Energy Society General Meeting, 2011 IEEE. IEEE, 2011, pp. 1-8. 